\title{
Overall survival and clinical characteristics of pancreatic cancer in BRCA mutation carriers
}

\author{
T Golan ${ }^{1,2,11}$, Z S Kanji $i^{3,4,11}$, R Epelbaum ${ }^{5,6}$, N Devaud ${ }^{3,4}$, E Dagan $^{7,8}$, S Holter ${ }^{3,4}$, D Aderka ${ }^{1,2}$, \\ S Paluch-Shimon ${ }^{1,2}$, B Kaufman ${ }^{1,2}$, R Gershoni-Baruch ${ }^{6,9}$, D Hedley ${ }^{3}$, M J Moore $^{3}$, E Friedman $^{\star 2,10}$ \\ and S Gallinger ${ }^{3,4}$
}

\begin{abstract}
${ }^{1}$ The Oncology Institute the Chaim Sheba Medical Center, Tel Hashomer, Israel; ${ }^{2}$ The Sackler School of Medicine, Tel Aviv University, Tel Aviv, Israel; ${ }^{3}$ Department of Surgery, University Health Network, Toronto, ON, Canada; ${ }^{4}$ Samuel Lunenfeld Research Institute of Mount Sinai Hospital, Toronto, ON, Canada; ${ }^{5}$ Department of Oncology, Rambam Health Care Campus, University of Haifa, Haifa, Israel; ${ }^{6}$ Technion, Faculty of Medicine, Haifa, Israel; ${ }^{7}$ Faculty of Social Welfare and Health Sciences, University of Haifa, Haifa, Israel; Institute of Human Genetics, Rambam Health Care Campus, University of Haifa, Haifa, Israel; ${ }^{9}$ Institute of Human Genetics, Rambam Health Care Campus, University of Haifa, Haifa, Israel and ${ }^{10}$ The Susanne Levy Gertner Oncogenetics Unit Chaim Sheba Medical Center, Tel Hashomer, Israel
\end{abstract}

Background: The BRCA1/2 proteins are involved in regulation of cellular proliferation by DNA damage repair via homologous recombination. Therefore, BRCA1/2 mutation carriers with pancreatic cancer may have distinct biologic outcomes.

Methods: Patients with BRCA1/2-associated pancreatic ductal adenocarcinoma (PDAC) diagnosed between January 1994 and
December 2012 were identified from databases at three participating institutions. Clinical data were collected. Disease-free
survival and overall survival (OS) were analysed.

Results: Overall, 71 patients with PDAC and BRCA1 $(n=21), \operatorname{BRCA2}(n=49)$ or both $(n=1)$ mutations were identified. Mean age at diagnosis was 60.3 years (range 33-83), 81.7\% ( $n=58)$ had any family history of malignancy; 30\% $(n=21)$ underwent primary resection. Out of 71 participants, 12 received experimental therapy; one patient had missing data, these 13 cases were excluded from OS analysis. Median OS for 58 patients was 14 months (95\% Cl 10-23 months). Median OS for patients with stage 1/2 disease has not been reached with 52\% still alive at 60 months. Median OS for stage 3/4 was 12 months ( $95 \% \mathrm{Cl} 6-15)$. Superior OS was observed for patients with stage $3 / 4$ treated with platinum vs those treated with non-platinum chemotherapies (22 vs 9 months; $P=0.039$ ).

Conclusion: Superior OS was observed for advanced-disease BRCA-associated PDAC with platinum exposure.

Familial clustering is found in $\sim 10 \%$ of pancreatic ductal adenocarcinoma (PDAC), often with an apparent autosomal dominant pattern of genetic transmission, suggestive of an inherited cancer syndrome (Shah and Kurtz, 2010). Pancreatic ductal adenocarcinoma is notably over-represented in families with a clustering of breast and ovarian cancers (Easton et al, 1996; Lal et al, 2000; Hahn et al, 2003; Friedenson, 2005). In a subset of these cancer-prone families, germline mutations in either the $B R C A 1$ or $B R C A 2$ genes are found, conferring a substantially higher lifetime risk for breast (50\%-85\% lifetime risk) and ovarian cancer (up to
$64 \%$ lifetime risk; King et al, 2003). The association of mutations in these two genes with increased risk to other cancer types is also well established (Giusti et al, 2003; Friedenson, 2005). The Breast Cancer Linkage Consortium reported estimated relative risks for PDAC in BRCA2 mutation carriers of 3.5 (95\% CI 1. 87-6.58; Easton, 1999). Recently, Narod et al reported a near doubling of risk for PDAC among BRCA1 and BRCA2 mutation carrier (Iqbal et al, 2012). Among Ashkenazi Jews, three predominant mutations in BRCA1 (185delAG, 5382InsC) and BRCA2 (6174delT) are detected in the majority of high-risk families, and also in $2.5 \%$ of

\footnotetext{
*Correspondence: Professor E Friedman; E-mail: eitan.friedman@sheba.health.gov.il

${ }^{11}$ These authors contributed equally to this work.
}

Received 10 February 2014; revised 19 June 2014; accepted 30 June 2014; published online 29 July 2014 
the general Ashkenazi population (Oddoux et al, 1996; Roa et al, 1996). The prevalence of the 6174delT BRCA2 mutation among Ashkenazi Jewish PDAC patients ranges from 5.5\% to $13 \%$ (Ozcelik et al, 1997; Figer et al, 2001; Ferrone et al, 2009). The prevalence of BRCA2 mutations in familial PDAC in non-Jewish, ethnically diverse populations has been reported to range from $6 \%$ to $17 \%$ (Murphy et al, 2002; Hahn et al, 2003; Couch et al, 2007).

The BRCA1 and BRCA2 proteins are involved in the regulation of cell cycle checkpoints in response to DNA damage, including the repair of DNA double-strand breaks via homologous recombination (HR; Venkitaraman, 2002). BRCA1/2-deficient cells that lack HR activity accumulate DNA double-strand breaks, resulting in genomic instability and an increased predisposition to malignant transformation and progression (Tutt and Ashworth, 2002). Somatic, biallelic inactivation of the BRCA1/2 genes confers sensitivity to inhibition of poly(ADP-ribose)-polymerase (PARP), an enzyme involved in base excision repair (Bryant et al, 2005) as the loss of both HR and PARP1 pathways leads to synthetic lethality during DNA replication. BRCA-defective cells are also more sensitive to platinums and anthracyclines, as these two agents are selectively lethal in HR-defective cells (Farmer et al, 2005; Tutt et al, 2005; van der Heijden et al, 2005). Thus, it seems plausible to hypothesise that BRCA1 and BRCA2 deficient tumours, particularly in $B R C A 1 / B R C A 2$ germline mutation carriers, have a distinct biologic and therapeutic outcome. Indeed, several previous studies suggested that BRCA-associated ovarian cancer patients have a more favourable clinical course than non-carriers, an observation attributable to an improved response to platinum-based chemotherapy (Cass et al, 2003; Chetrit et al, 2008; Tan et al, 2008; Vencken et al, 2011). However, a differential therapeutic response to chemotherapy in BRCA mutation carriers was not replicated in all studies (Robson et al, 2004; Rennert et al, 2007; Lee et al, 2011).

The prognostic and predictive marker of germline BRCAassociated PDAC are unknown. The purpose of this study was to investigate the impact of germline BRCA1 and BRCA2 mutations on the natural history and therapeutic outcome, with the use of platinum agents, in patients with PDAC.

\section{MATERIALS AND METHODS}

Patient identification and data collection. Patients with BRCA1/ 2-associated PDAC diagnosed between January 1994 and December 2012 were identified from clinical databases at three participating institutions: Rambam Medical Institute, Haifa; Princess Margaret Hospital, Toronto, Ontario; and Chaim Sheba Medical Center, Ramat Gan. Data on patient demographics, clinical history, past surgical procedures specifically pertaining to PDAC, systemic chemotherapy and response to treatment were abstracted from patient records. Clinical stage was classified according to the seventh edition of the American Joint Committee on Cancer staging criteria (Edge and Compton, 2010). The institutional review board (IRB) of each participating institute approved this study.

DNA extraction. Genomic DNA was prepared from anticoagulated venous blood, using PUREGene DNA extraction kit (Gentra Systems Inc., Minneapolis, MN, USA) following the manufacturer's recommended protocol or by organic solvent isolation.

Analysis of the founder Jewish mutations in BRCA1 and BRCA2. At the Rambam and Chaim Sheba Medical Centers, mutational analyses for the three predominantly Jewish mutations (185delAG, 5382InsC in BRCA1 and 6174delT in BRCA2) were carried out by restriction enzyme digest of polymerase chain reaction (PCR) products, and analysis of the digested PCR products on agarose gels was carried out, as described previously (Ozcelik et al, 1997; Rohlfs et al, 1997). For each of these three mutations, a known mutation carrier was used as a positive control in each experiment.

At the Princess Margaret Hospital in Toronto, mutational analysis of exons and flanking regions of the BRCA1 and BRCA2 loci was carried out at the Advanced Molecular Diagnostics Laboratory at Mount Sinai Hospital. Polymerase chain reaction was carried out in $12 \mu \mathrm{l}$ reaction volumes. Polymerase chain reaction primers and conditions are available upon request.

Following PCR clean-up, BigDyeTerminator Cycle Sequencing Version 3.1 (Applied Biosystems, Toronto, ON, Canada) was used for sequencing reactions using $2 \mu \mathrm{l}$ of the cleaned up PCR products and using the recommended protocol for cycle sequencing, and analysed on an ABI 3730XL Genetic Analyzer (Applied Biosystems, Toronto, ON, Canada). Sequencing files were processed using SequenceAnalysis software (Applied Biosystems, Toronto, ON, Canada) and assembled and analysed using Mutation Surveyor (version 4.0.7, SoftGenetics, LLC, State College, PA, USA). The GenBank reference sequences used for this study were NM_007294.3 for BRCA1 and NM_000059.3 for BRCA2.

Overall survival and disease-free survival. Overall survival (OS) was defined as the time from the date of diagnosis to the date of death from any cause. If a patient is not known to have died, the OS was censored until the date of last follow-up. The OS results for patients exposed to platinum-based treatments during the course of their disease were compared with that of non-platinum chemotherapy-treated carriers. Disease-free survival (DFS) was defined as the time from the date of diagnosis to the date of recurrence in stage 1 and 2 patients. If a patient did not have an event, DFS was censored at the date of last follow-up.

Statistical analysis. Distributions for categorical variables were compared and analysed by the Fisher-Irwin exact test. The KaplanMeier (KM) model was used to calculate OS, and DFS as a function of time. The differences between the KM curves were tested for significance with the use of the log-rank test. All statistical tests were analysed to a significance level of 0.05 using the STATA statistical package (StataCorp LP, College Station, TX, USA).

\section{RESULTS}

Patient and tumour characteristics. Overall, 71 patients with BRCA1/2-associated PDAC diagnosed between January 1994 and December 2012 were identified. Mean age at diagnosis was 60.3 years (range $33-83$ years), 58\% $(n=41)$ were male and $73.2 \%$ $(n=52)$ were Jewish (Table 1$)$. Stage 1 disease was identified in a single patient (1.4\%), whereas stage 2,3 and 4 disease were observed in $19(27 \%), 16(23 \%)$ and $34(48 \%)$ of the patients, respectively (one patient had missing data). A primary resection was performed in $30 \%(n=21)$ of patients. One patient had metastatic disease at resection and therefore was included in survival data for advanced disease. The clinical characteristics of the subgroup of the 58 patients (excluding the patients treated with PARP inhibitors) is similar to the whole cohort (Table 1).

Of all study participants, $69 \%(n=49)$ had a BRCA2 mutation, $30 \%(n=21)$ a BRCA1 mutation and $1 \%(n=1)$ had both a $B R C A 1$ and a BRCA2 mutation. Specific mutations are listed in Table 2. In total, 22 patients in the stage $3 / 4$ group received platinum-based treatment. The majority of our platinum-treated patients received gemcitabine and cisplatin, one patient received gemcitabine and oxaliplatin and three patients received FOLFIRINOX (oxaliplatin, irinotecan, folinic acid and fluorouracil).

Family history of cancer. Most of the study participants $(58 / 71,82 \%)$ had a family history of cancer, of which $91 \%$ $(53 / 58)$ had an affected first-degree relative, and 33\% (19/58) had a family history of a first or second-degree relative with PDAC. The 


\begin{tabular}{|c|c|c|}
\hline Demographic & All patients (\%) & $\begin{array}{l}\text { Patients with } \\
\text { OS data (\%) }\end{array}$ \\
\hline Number of patients & 71 & 58 \\
\hline \multicolumn{3}{|l|}{ Gender } \\
\hline $\begin{array}{l}\text { Male } \\
\text { Female }\end{array}$ & $\begin{array}{l}41(57.8) \\
30(42.2)\end{array}$ & $\begin{array}{l}33(56.9) \\
25(43.1)\end{array}$ \\
\hline \multicolumn{3}{|l|}{ Age (at diagnosis) } \\
\hline $\begin{array}{l}\text { Mean } \pm \text { s.d. (years) } \\
\text { Range (years) }\end{array}$ & $\begin{array}{c}60.3 \pm 10.0 \\
33-83\end{array}$ & $\begin{array}{c}61.6 \pm 9.9 \\
33-82\end{array}$ \\
\hline \multicolumn{3}{|l|}{ Jewish } \\
\hline $\begin{array}{l}\text { Yes } \\
\text { No } \\
\text { Missing }\end{array}$ & $\begin{array}{c}52(73.2) \\
18(25.4) \\
1(1.4)\end{array}$ & $\begin{array}{l}41(70.7) \\
17(29.3)\end{array}$ \\
\hline Jewish ethnicity & 52 & \\
\hline Ashkenazi & 47 (90.4) & $39(95.2)$ \\
\hline Non-Ashkenazi & $2(3.9)$ & \\
\hline Mixed & $2(3.9)$ & $1(2.4)$ \\
\hline Missing & $1(1.8)$ & $1(2.4)$ \\
\hline Not Jewish & 18 & \\
\hline Caucasian & $13(72.2)$ & $12(70.6)$ \\
\hline Other & $5(27.8)$ & $5(29.4)$ \\
\hline
\end{tabular}

family history for one patient was unknown. Thirty-seven percent of patients in our cohort $(26 / 70)$ also had a personal history of a malignancy including breast $(n=16)$, prostate $(n=3)$, renal cell carcinoma $(n=2)$, malignant melanoma $(n=1)$, ovarian $(n=1)$, endometrial $(n=1)$, thyroid $(n=1)$, bladder $(n=1)$ and colon cancer $(n=1)$. One patient had both breast and endometrial cancer (Table 3$)$.

Disease-free survival and overall survival. In our cohort, $28.2 \%$ of patients $(n=20)$ had early-stage disease (stage 1 or 2 ) and underwent curative intent resection. The median DFS for this group was 13 months (95\% CI 6-19 months). The probabilities that a patient remained disease free at 1 and 5 years were $0.54(95 \%$ CI $0.29-0.74$ ) and 0.27 (95\% CI 0.09-0.5), respectively.

The median OS (mOS) of patients with a BRCA1 and BRCA2 mutations was 15 months (range 4-27 months) and 13 months (range 9-23 months), respectively. This difference was not significant $(P=0.77$; Figure $1 \mathrm{~B})$.

Out of 71 participants, 12 received experimental therapy (PARP inhibitors) and 1 patient had missing data; these 13 cases were excluded from OS analysis. Patients treated with PARP inhibitors were excluded from OS analysis since these data that have been acquired in the course of a clinical trial have not yet been published. Median OS for the remaining 58 eligible patients was 14 months (95\% CI 10-23 months; Figure 1A). No significant difference in median OS was observed in Jewish patients 13 months (95\% CI 5-22 months) in comparison to non-Jewish patients 15 months (95\% CI 8-60 months). Among 15 patients with early disease (stage $1 / 2$ ), the probability that a patient with early-stage disease remained alive at 5 years was 0.52 (CI $0.18-0.78$; Figure $2 \mathrm{~A}$ ), and the probability that patients with advanced disease $(n=43)$ remained alive at 5 years was 0.11 with (C.I $0.02-0.28)$. The mOS in combined stage 3 and 4 disease was 12 months (range 6-15 months; Figure 2B).

\begin{tabular}{|c|c|c|}
\hline Specific mutation & $\begin{array}{l}\text { Number of } \\
\text { patients }\end{array}$ & BRCA1/2 \\
\hline 185delAG & 14 & BRCA1 \\
\hline 5382insC & 4 & BRCA1 \\
\hline 2318delG & 1 & BRCA1 \\
\hline $4237 \mathrm{C}>\mathrm{T}$ & 1 & BRCA1 \\
\hline c.1-?80+?dup & 1 & BRCA1 \\
\hline 6174delT & 31 & BRCA2 \\
\hline 4075delGT & 1 & BRCA2 \\
\hline $\begin{array}{l}\text { c3645-3646delinsTAAAAAG } \\
\text { p.Phe1216LysfsX14 }\end{array}$ & 1 & BRCA2 \\
\hline 2041 ins A & 1 & BRCA2 \\
\hline 5996dupT & 1 & BRCA2 \\
\hline 6589delAG & 1 & BRCA2 \\
\hline c.8332-?-8487+ ?del, exon 19 deleted & 1 & BRCA2 \\
\hline 3393delC & 1 & BRCA2 \\
\hline 8765delAG & 1 & BRCA2 \\
\hline 3967 delA & 1 & BRCA2 \\
\hline $\mathrm{IVS7}+2 \mathrm{~T}>\mathrm{G}$ & 1 & BRCA2 \\
\hline $4003 \mathrm{G}>\mathrm{T}$ & 1 & BRCA2 \\
\hline $7908 \mathrm{~T}>\mathrm{A}$ & 1 & BRCA2 \\
\hline $9118-1 \mathrm{G}>\mathrm{C}$ & 1 & BRCA2 \\
\hline 2041 delA & 1 & BRCA2 \\
\hline 262_263delCT & 1 & BRCA2 \\
\hline 2957_2958insG & 1 & BRCA2 \\
\hline 5722_5723delCT & 1 & BRCA2 \\
\hline $1736 \mathrm{~T}>\mathrm{G}$ & 1 & BRCA2 \\
\hline $\begin{array}{l}\text { c.2681_2682delAA, p.K894TfsX8/ } \\
\text { c.9382C>T, p.R3128X }\end{array}$ & 1 & BRCA1 +2 \\
\hline
\end{tabular}

\section{Table 3. Family history of malignancies}

\begin{tabular}{|l|c|}
\hline Family history of cancer & Patients (\%) \\
\hline Yes & $58(81.7)$ \\
\hline No & $12(16.9)$ \\
\hline Missing & $1(1.4)$ \\
\hline
\end{tabular}

\section{Family history of PDAC}

\begin{tabular}{|l|c|}
\hline Number of patients & 58 \\
Yes & $19(32.7)$ \\
No & $35(60.3)$ \\
Missing & $4(7.0)$
\end{tabular}

\section{First-degree relative with cancer}

Number of patients

Yes

No

Missing

Abbreviation: PDAC $=$ pancreatic ductal adenocarcinoma

Median OS for stage 3 patients $(n=8)$ treated with platinum agents was over 48 months, compared to 10 months for those exposed to only non-platinum agents $(n=7, P=0.205$; 

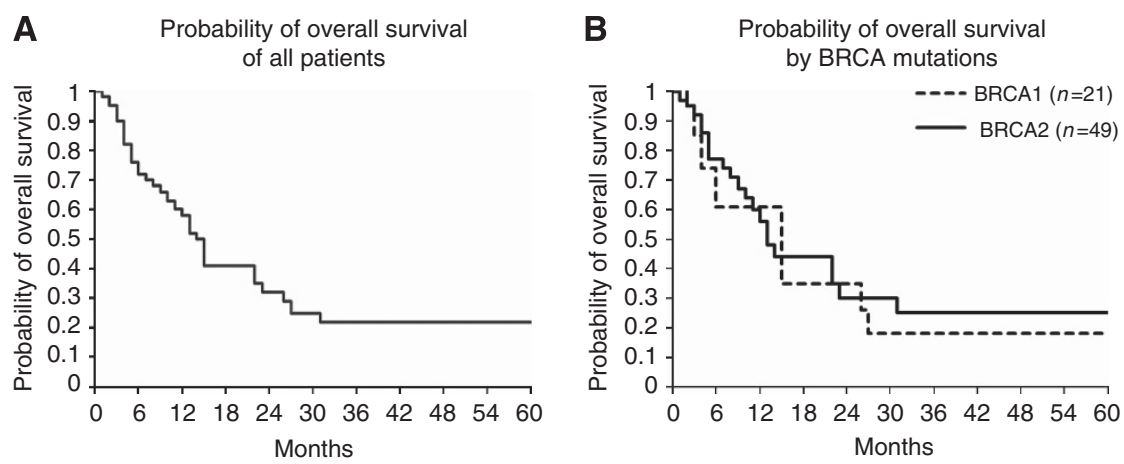

Figure 1. (A) Probability of overall survival of all patients. (B) Probability of overall survival by BRCA mutations.
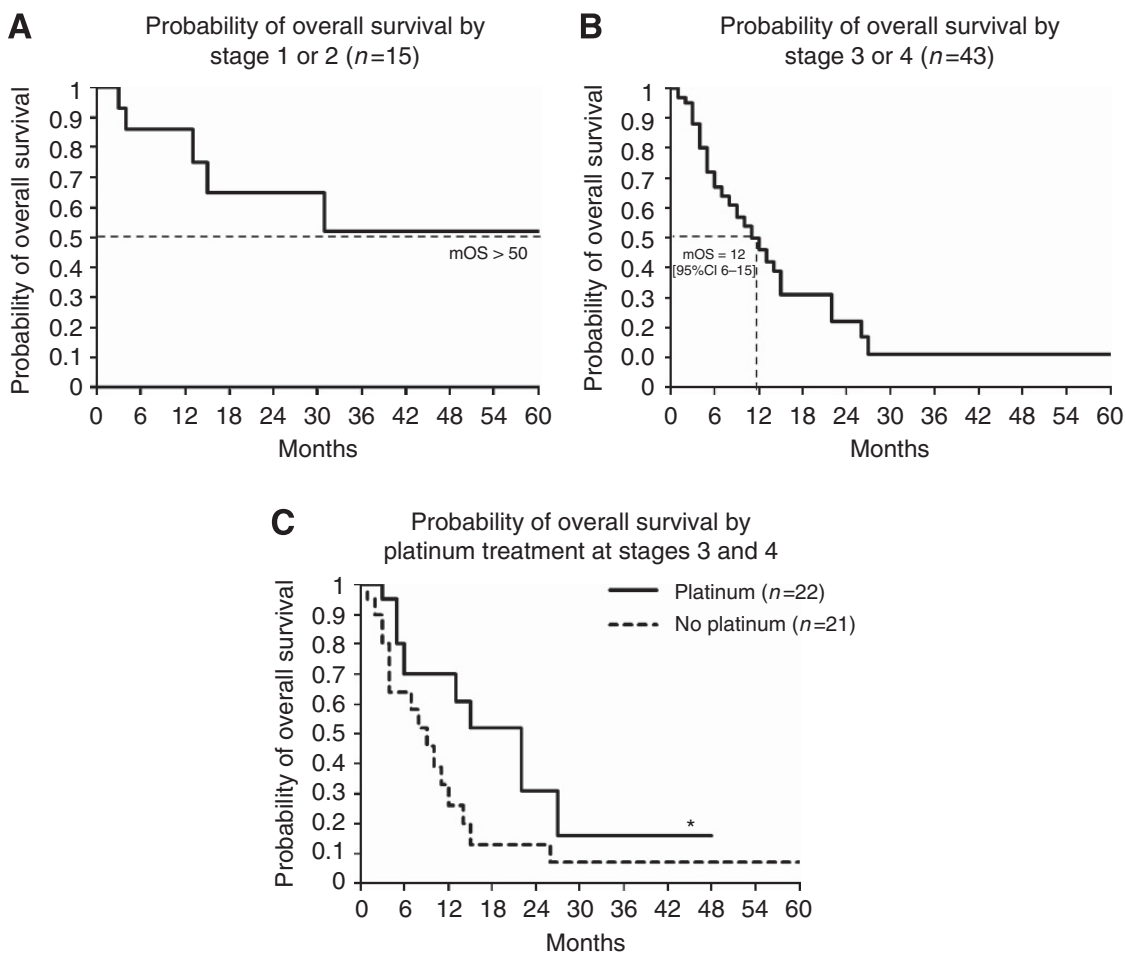

Figure 2. (A) Probability of overall survival by stage 1 or $2(n=15)$. (B) Probability of overall survival by stage 3 or 4 ( $n=43$ ). (C) Probability of overall survival by platinum treatment at stages 3 and 4 .

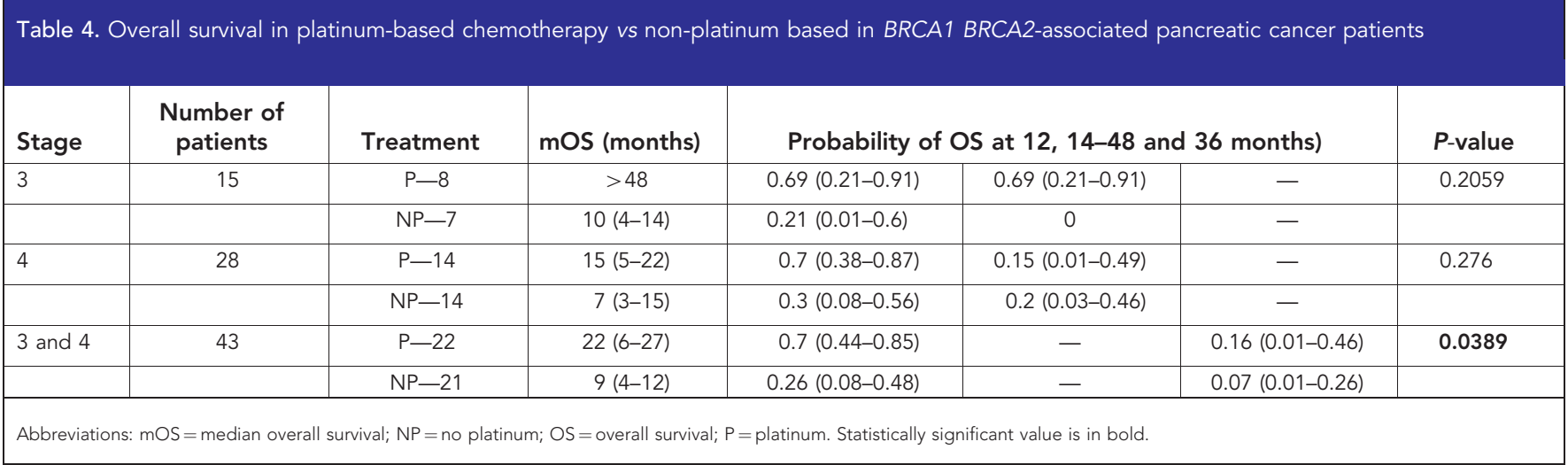

Table 4). In patients with stage 4 disease, mOS of platinumtreated patients $(n=14)$ was 15 months compared with 7 months for those treated with only non-platinum-treated patient
( $n=14, P=0.276)$. When combining data for stages 3 and 4 , the mOS was 22 months for the platinum exposed $(n=22)$ compared with 9 months for the non-platinum $(n=21)$ 
treatment groups $(P<0.039$; Figure 2C). Overall survival probabilities are shown in Table 4.

\section{DISCUSSION}

Our data suggest that $B R C A$ mutation status is an important clinical factor in PDAC and that BRCA mutation status may be an important prognostic and predictive biomarker for PDAC.

The median age of diagnosis was a decade younger than an unselected population reported from the Surveillance, Epidemiology, and End Results (Howlader et al, 2012). The effect of germline $B R C A 1 / 2$ mutations on clinical course and therapeutic outcome compared to sporadic, $B R C A 1 / 2$ wild type, subjects has previously been reported in a variety of cancer types. The prognostic significance of $B R C A 1$ or $B R C A 2$-associated PDAC is currently unknown. In ovarian cancer, a significantly longer OS has been reported for $B R C A$ mutation carriers compared with non-carriers (53.7 months vs 37.9 months, $P=0.002$ ), with a more pronounced effect for patients with advanced stage, higher grade disease (Chetrit et al, 2008). In a study of 1545 consecutive Ashkenazi Jewish breast cancer patients, of whom $10 \%$ were BRCA carriers, no survival difference was noted between carriers and non-carriers (Rennert et al, 2007). In addition, similar outcomes were identified for BRCA mutation breast cancer carriers and sporadic cases in a large multivariate analysis (Goodwin et al, 2012). In our study, we observed a slightly more favourable outcome in the setting of being a BRCA1/2 mutation carrier in PDAC patients. Historical controls report an mOS of 4.4 months (Bilimoria et al, 2007) yet in the present study, median all-stage OS of 58 PARP inhibitor naive patients was 14 months. Therefore our preliminary data suggest that BRCA1 or BRCA2-associated PDAC has more favourable outcome than non-BRCA-associated PDAC.

The main finding in our study is an improvement in OS in stage 3 and 4 BRCA1 or BRCA2-associated PDAC patients who were treated with platinum-based agents compared with those who were not treated with these agents. It is worth noting that previous clinical trials have not shown an OS benefit with the combination of platinum agents and gemcitabine in advanced pancreatic cancer(Heinemann et al, 2006; Poplin et al, 2009). Our results suggested a more favourable outcome with platinum treatment for each individual stage; however, these differences were not statistically significant.

The effect of BRCA mutations and response to DNA crosslinking agents in PDAC was evaluated by Lowery et al (2011), who reported that 5/6 BRCA-associated PDAC patients who received a platinum agent as first-line metastatic therapy demonstrated a partial or complete radiographic response. This favourable response of BRCA-associated PDAC to DNA crosslinking agents is also supported by a case report by Sonnenblick (2011). Similarly, a survival advantage with platinum-containing regimens was reported for patients with PDAC and a family history of any malignancy, in whom the status of BRCA mutation carrier status was not specified (Oliver et al, 2010).

These reports, together with our findings, highlight the potential biological importance of treating tumours with deficient $\mathrm{HR}$ pathway with DNA crosslinking agents. Future studies should consider the use of cisplatin, in combination with other agents that selectively kill error-prone, HR-defective cells such as cyclophosphamide, temozalomide and PARP inhibitors (Evers et al, 2010). Importantly, these studies should also address differential individual patient sensitivity and de novo or acquired resistance to cisplatin using assays that reflect relative genetic instability (low or high copy number alteration, expression of other DNA repair genes, RAD51 nuclear foci as surrogate markers for $\mathrm{HR}$ and BRCA1/2-genetic reversion; Bouwman et al, 2010; Dent and Bristow, 2011; Vollebergh et al, 2012).
The present study is the largest cohort to date that has been reported with BRCA1/2-associated PDAC patients. As PARP inhibitors are being introduced to PDAC patients harbouring BRCA mutations, in the context of clinical trials, the assembly and analysis of similar data will be difficult; therefore, our observations may remain unique and difficult to replicate. The majority of our patients in the platinum-based group received gemcitabine and cisplatin, therefore we cannot conclude from our data whether the doublet combination with platinum is sufficient for BRCAassociated PDAC or whether the new FOLFIRINOX combination is superior. Previously reported data, combined with data reported herein on the superior therapeutic response to platinum-based chemotherapy in BRCA-associated PDAC, needs to be interpreted with caution for several reasons: the non-randomised, retrospective nature of these studies, the limited sample sizes, the comparison to historic controls and the variation in chemotherapy regimens both within and between sites including the use of different platinum agents, dosing schedules, dosing frequency and improvement in chemotherapy drugs over the past decade. In addition, the majority of our patients were of Ashkenazi Jewish descent, and this limits the general applicability of our findings to ethnically diverse PDAC patients with a different spectrum of $B R C A 1 / 2$ mutations. Nonetheless, our experiences in non-Israeli cancer centres, suggest similar positive responses to platinum-based therapies for other ethnic groups with BRCA-associated PDAC.

In conclusion, the current study suggests that $B R C A$ mutation status may be a prognostic and predictive biomarker for PDAC and that BRCA-associated PDAC patients may benefit from the addition of platinum agents to standard therapy. Our data have not definitely shown this in all stages and it would be beneficial to further investigate early stage $v$ s late stage in a case-control study. A randomised phase II clinical trial evaluating the addition of PARP inhibition to platinum-based therapy in a genetically selected population of $B R C A 1, B R C A 2$ or PALB2 mutation carriers with PDAC is currently underway to further address this clinical issue (NCT01585805).

\section{ACKNOWLEDGEMENTS}

We would like to thank Teresa Selander and the Biospecimen Repository at Mount Sinai Hospital, and Dr Jordan Lerner-Ellis, Rishi Jairath and members of the Advanced Molecular Diagnostics Laboratory at Mount Sinai Hospital for assistance with BRCA mutation sequencing. We would also like to thank Adva Goldshtain at Clinical Trial Unit at Sheba Medical Center for assistance with clinical data retrieval and Yael Laitman from the Oncogenetics unit for DNA processing, storing and genotyping.

\section{CONFLICT OF INTEREST}

The authors declare no conflict of interest.

\section{REFERENCES}

Bilimoria KY, Bentrem DJ, Ko CY, Ritchey J, Stewart AK, Winchester DP, Talamonti MS (2007) Validation of the 6th edition AJCC Pancreatic Cancer Staging System: report from the National Cancer Database. Cancer 110: $738-744$.

Bouwman P, Aly A, Escandell JM, Pieterse M, Bartkova J, Van Der Gulden H, Hiddingh S, Thanasoula M, Kulkarni A, Yang Q, Haffty BG, Tommiska J, Blomqvist C, Drapkin R, Adams DJ, Nevanlinna H, Bartek J,

Tarsounas M, Ganesan S, Jonkers J (2010) 53BP1 loss rescues BRCA1 deficiency and is associated with triple-negative and BRCA-mutated breast cancers. Nat Struct Mol Biol 17: 688-695. 
Bryant HE, Schultz N, Thomas HD, Parker KM, Flower D, Lopez E, Kyle S, Meuth M, Curtin NJ, Helleday T (2005) Specific killing of BRCA2deficient tumours with inhibitors of poly(ADP-ribose) polymerase. Nature 434: 913-917.

Cass I, Baldwin RL, Varkey T, Moslehi R, Narod SA, Karlan BY (2003) Improved survival in women with BRCA-associated ovarian carcinoma. Cancer 97: 2187-2195.

Chetrit A, Hirsh-Yechezkel G, Ben-David Y, Lubin F, Friedman E, Sadetzki S (2008) Effect of BRCA1/2 mutations on long-term survival of patients with invasive ovarian cancer: the national Israeli study of ovarian cancer. J Clin Oncol 26: 20-25.

Couch FJ, Johnson MR, Rabe KG, Brune K, De Andrade M, Goggins M, Rothenmund H, Gallinger S, Klein A, Petersen GM, Hruban RH (2007) The prevalence of BRCA2 mutations in familial pancreatic cancer. Cancer Epidemiol Biomarkers Prev 16: 342-346.

Dent RA, Bristow RG (2011) In situ DNA repair assays as guides to personalized breast cancer chemotherapeutics: ready for prime time? J Clin Oncol 29: 2130-2132.

Easton DF (1999) Cancer risks in BRCA2 mutation carriers. The Breast Cancer Linkage Consortium. J Natl Cancer Inst 91: 1310-1316.

Easton DF, Matthews FE, Ford D, Swerdlow AJ, Peto J (1996) Cancer mortality in relatives of women with ovarian cancer: the OPCS Study. Office of Population Censuses and Surveys. Int J Cancer 65: 284-294.

Edge SB, Compton CC (2010) The American Joint Committee on Cancer: the 7th edition of the AJCC cancer staging manual and the future of TNM. Ann Surg Oncol 17: 1471-1474.

Evers B, Schut E, van der Burg E, Braumuller TM, Egan DA, Holstege H, Edser P, Adams DJ, Wade-Martins R, Bouwman P, Jonkers J (2010) A high-throughput pharmaceutical screen identifies compounds with specific toxicity against BRCA2-deficient tumors. Clin Cancer Res 16: $99-108$.

Farmer H, Mccabe N, Lord CJ, Tutt AN, Johnson DA, Richardson TB, Santarosa M, Dillon KJ, Hickson I, Knights C, Martin NM, Jackson SP, Smith GC, Ashworth A (2005) Targeting the DNA repair defect in BRCA mutant cells as a therapeutic strategy. Nature 434: 917-921.

Ferrone CR, Levine DA, Tang LH, Allen PJ, Jarnagin W, Brennan MF, Offit K, Robson ME (2009) BRCA germline mutations in Jewish patients with pancreatic adenocarcinoma. J Clin Oncol 27: 433-438.

Figer A, Irmin L, Geva R, Flex D, Sulkes J, Sulkes A, Friedman E (2001) The rate of the 6174delT founder Jewish mutation in BRCA2 in patients with non-colonic gastrointestinal tract tumours in Israel. Br J Cancer 84: $478-481$.

Friedenson B (2005) BRCA1 and BRCA2 pathways and the risk of cancers other than breast or ovarian. MedGenMed 7: 60 .

Giusti RM, Rutter JL, Duray PH, Freedman LS, Konichezky M, Fisher-Fischbein J, Greene MH, Maslansky B, Fischbein A, Gruber SB, Rennert G, Ronchetti RD, Hewitt SM, Struewing JP, Iscovich J (2003) A twofold increase in BRCA mutation related prostate cancer among Ashkenazi Israelis is not associated with distinctive histopathology. J Med Genet 40: 787-792.

Goodwin PJ, Phillips KA, West DW, Ennis M, Hopper JL, John EM, O'malley FP, Milne RL, Andrulis IL, Friedlander ML, Southey MC, Apicella C, Giles GG, Longacre TA (2012) Breast cancer prognosis in BRCA1 and BRCA2 mutation carriers: an International Prospective Breast Cancer Family Registry population-based cohort study. J Clin Oncol 30: $19-26$.

Hahn SA, Greenhalf B, Ellis I, Sina-Frey M, Rieder H, Korte B, Gerdes B, Kress R, Ziegler A, Raeburn JA, Campra D, Grutzmann R, Rehder H, Rothmund M, Schmiegel W, Neoptolemos JP, Bartsch DK (2003) BRCA2 germline mutations in familial pancreatic carcinoma. J Natl Cancer Inst 95: 214-221.

Heinemann V, Quietzsch D, Gieseler F, Gonnermann M, Schonekas H, Rost A, Neuhaus H, Haag C, Clemens M, Heinrich B, Vehling-Kaiser U, Fuchs M, Fleckenstein D, Gesierich W, Uthgenannt D, Einsele H, Holstege A, Hinke A, Schalhorn A, Wilkowski R (2006) Randomized phase III trial of gemcitabine plus cisplatin compared with gemcitabine alone in advanced pancreatic cancer. J Clin Oncol 24: 3946-3952.

Howlader N, Noone AM, Krapcho M, Neyman N, Aminou R, Waldron W, Altekruse SF, Kosary CL, Ruhl J, Tatalovich Z, Cho H, Mariotto A, Eisner MP, Lewis DR, Chen HS (2012) SEER Cancer Statistics Review, 1975-2009 (Vintage 2009 Populations). Available at http://seer.cancer.gov/ archive/csr/1975_2009_pops09/.
Iqbal J, Ragone A, Lubinski J, Lynch HT, Moller P, Ghadirian P, Foulkes WD, Armel S, Eisen A, Neuhausen SL, Senter L, Singer CF, Ainsworth P, Kim-Sing C, Tung N, Friedman E, Llacuachaqui M, Ping S, Narod SA (2012) The incidence of pancreatic cancer in BRCA1 and BRCA2 mutation carriers. Br J Cancer 107: 2005-2009.

King MC, Marks JH, Mandell JB (2003) Breast and ovarian cancer risks due to inherited mutations in BRCA1 and BRCA2. Science 302: 643-646.

Lal G, Liu G, Schmocker B, Kaurah P, Ozcelik H, Narod SA, Redston M, Gallinger S (2000) Inherited predisposition to pancreatic adenocarcinoma: role of family history and germ-line p16, BRCA1, and BRCA2 mutations. Cancer Res 60: 409-416.

Lee LJ, Alexander B, Schnitt SJ, Comander A, Gallagher B, Garber JE, Tung N (2011) Clinical outcome of triple negative breast cancer in BRCA1 mutation carriers and noncarriers. Cancer 117: 3093-3100.

Lowery MA, Kelsen DP, Stadler ZK, Yu KH, Janjigian YY, Ludwig E, D'adamo DR, Salo-Mullen E, Robson ME, Allen PJ, Kurtz RC, O'reilly EM (2011) An emerging entity: pancreatic adenocarcinoma associated with a known BRCA mutation: clinical descriptors, treatment implications, and future directions. Oncologist 16: 1397-1402.

Murphy KM, Brune KA, Griffin C, Sollenberger JE, Petersen GM, Bansal R, Hruban RH, Kern SE (2002) Evaluation of candidate genes MAP2K4, MADH4, ACVR1B, and BRCA2 in familial pancreatic cancer: deleterious BRCA2 mutations in 17\%. Cancer Res 62: 3789-3793.

Oddoux C, Struewing JP, Clayton CM, Neuhausen S, Brody LC, Kaback M, Haas B, Norton L, Borgen P, Jhanwar S, Goldgar D, Ostrer H, Offit K (1996) The carrier frequency of the BRCA2 6174delT mutation among Ashkenazi Jewish individuals is approximately $1 \%$. Nat Genet $\mathbf{1 4}$ : 188-190.

Oliver GR, Sugar E, Laheru D, Diaz LA (2010) Family history of cancer and sensitivity to platinum chemotherapy in pancreatic adenocarcinoma. Gastrointestinal Cancers Symposium. Orlando, FL, USA. January 22-24, 2010, Abstract no:180.

Ozcelik H, Schmocker B, Di Nicola N, Shi XH, Langer B, Moore M, Taylor BR, Narod SA, Darlington G, Andrulis IL, Gallinger S, Redston M (1997) Germline BRCA2 6174delT mutations in Ashkenazi Jewish pancreatic cancer patients. Nat Genet 16: 17-18.

Poplin E, Feng Y, Berlin J, Rothenberg ML, Hochster H, Mitchell E, Alberts S, O'dwyer P, Haller D, Catalano P, Cella D, Benson 3rd AB (2009) Phase III, randomized study of gemcitabine and oxaliplatin versus gemcitabine (fixed-dose rate infusion) compared with gemcitabine (30-minute infusion) in patients with pancreatic carcinoma E6201: a trial of the Eastern Cooperative Oncology Group. J Clin Oncol 27: 3778-3785.

Rennert G, Bisland-Naggan S, Barnett-Griness O, Bar-Joseph N, Zhang S, Rennert HS, Narod SA (2007) Clinical outcomes of breast cancer in carriers of BRCA1 and BRCA2 mutations. N Engl J Med 357: 115-123.

Roa BB, Boyd AA, Volcik K, Richards CS (1996) Ashkenazi Jewish population frequencies for common mutations in BRCA1 and BRCA2. Nat Genet 14: 185-187.

Robson ME, Chappuis PO, Satagopan J, Wong N, Boyd J, Goffin JR, Hudis C, Roberge D, Norton L, Begin LR, Offit K, Foulkes WD (2004) A combined analysis of outcome following breast cancer: differences in survival based on BRCA1/BRCA2 mutation status and administration of adjuvant treatment. Breast Cancer Res 6: R8-R17.

Rohlfs EM, Learning WG, Friedman KJ, Couch FJ, Weber BL, Silverman LM (1997) Direct detection of mutations in the breast and ovarian cancer susceptibility gene BRCA1 by PCR-mediated site-directed mutagenesis. Clin Chem 43: 24-29.

Shah MA, Kurtz RC (2010) Upper gastrointestinal cancer predisposition syndromes. Hematol Oncol Clin North Am 24: 815-835.

Sonnenblick A, Kadouri L, Appelbaum L, Peretz T, Sagi M, Goldberg Y, Hubert A (2011) Complete remission, in BRCA2 mutation carrier with metastatic pancreatic adenocarcinoma, treated with cisplatin based therapy. Cancer Biol Ther 12: 165-168.

Tan DS, Rothermundt C, Thomas K, Bancroft E, Eeles R, Shanley S, Ardern-Jones A, Norman A, Kaye SB, Gore ME (2008) "BRCAness" syndrome in ovarian cancer: a case-control study describing the clinical features and outcome of patients with epithelial ovarian cancer associated with BRCA1 and BRCA2 mutations. J Clin Oncol 26: 5530-5536.

Tutt A, Ashworth A (2002) The relationship between the roles of BRCA genes in DNA repair and cancer predisposition. Trends Mol Med 8: 571-576.

Tutt AN, Lord CJ, Mccabe N, Farmer H, Turner N, Martin NM, Jackson SP, Smith GC, Ashworth A (2005) Exploiting the DNA repair defect in BRCA 
mutant cells in the design of new therapeutic strategies for cancer. Cold Spring Harb Symp Quant Biol 70: 139-148.

van der Heijden MS, Brody JR, Dezentje DA, Gallmeier E, Cunningham SC, Swartz MJ, Demarzo AM, Offerhaus GJ, Isacoff WH, Hruban RH, Kern SE (2005) In vivo therapeutic responses contingent on Fanconi anemia/ BRCA2 status of the tumor. Clin Cancer Res 11: 7508-7515.

Vencken PM, Kriege M, Hoogwerf D, Beugelink S, van der Burg ME,

Hooning MJ, Berns EM, Jager A, Collee M, Burger CW, Seynaeve C (2011) Chemosensitivity and outcome of BRCA1- and BRCA2-associated ovarian cancer patients after first-line chemotherapy compared with sporadic ovarian cancer patients. Ann Oncol 22: 1346-1352.
Venkitaraman AR (2002) Cancer susceptibility and the functions of BRCA1 and BRCA2. Cell 108: 171-182.

Vollebergh MA, Jonkers J, Linn SC (2012) Genomic instability in breast and ovarian cancers: translation into clinical predictive biomarkers. Cell Mol Life Sci 69: 223-245.

This work is published under the standard license to publish agreement. After 12 months the work will become freely available and the license terms will switch to a Creative Commons AttributionNonCommercial-Share Alike 3.0 Unported License. 